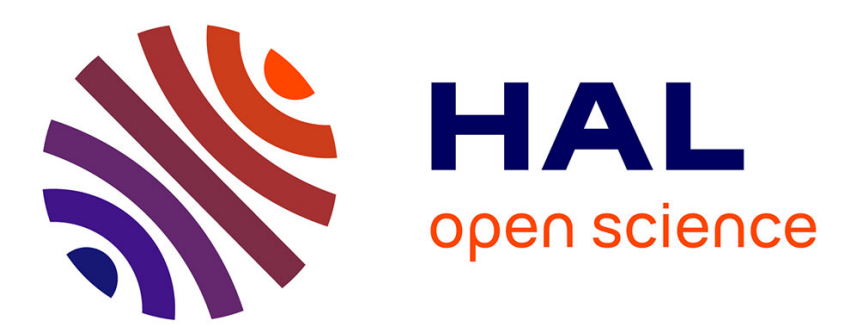

\title{
Photosensitized reactions initiated by 6-carboxypterin: singlet and triplet reactivity
}

\author{
L. Tinel, S. Rossignol, R. Ciuraru, S. Dumas, C. George
}

\section{To cite this version:}

L. Tinel, S. Rossignol, R. Ciuraru, S. Dumas, C. George. Photosensitized reactions initiated by 6carboxypterin: singlet and triplet reactivity. Physical Chemistry Chemical Physics, 2016, 18 (25), pp.17105-15. 10.1039/c6cp03119f . hal-01343458

\section{HAL Id: hal-01343458 \\ https://hal.science/hal-01343458}

Submitted on 13 Oct 2021

HAL is a multi-disciplinary open access archive for the deposit and dissemination of scientific research documents, whether they are published or not. The documents may come from teaching and research institutions in France or abroad, or from public or private research centers.
L'archive ouverte pluridisciplinaire HAL, est destinée au dépôt et à la diffusion de documents scientifiques de niveau recherche, publiés ou non, émanant des établissements d'enseignement et de recherche français ou étrangers, des laboratoires publics ou privés. 


\section{Photosensitized reactions initiated by 6-carboxypterin: singlet and triplet reactivity}

L. Tinel ${ }^{\mathrm{a}}$, S. Rossignol ${ }^{\mathrm{a}}$, R. Ciuraru ${ }^{\mathrm{a}, \mathrm{b}}$, S. Dumas ${ }^{\mathrm{a}}$, C. George ${ }^{\mathrm{a},{ }^{*}}$

a.Université Lyon 1, CNRS, UMR 5256, IRCELYON, Institut de recherches sur la catalyse et l'environnement de Lyon, 2 avenue Albert Einstein, F-69626 Villeurbanne, France

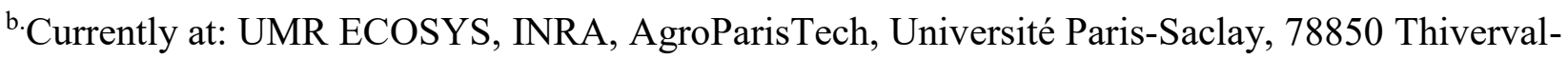
Grignon, France

*Email: christian.george@ircelyon.univ-lyon1.fr, Tel: +33-472-445-492 


\begin{abstract}
Pterins, derivatives of 2-aminopteridin-4(3H)-one, are natural photosensitizers, common to many biological systems. Indications that these photosensitizers are also present in the sea-surface microlayer motivated the study of the photophysical and photochemical properties of 6carboxypterin (CPT), which was chosen as a model for this group of photoactive compounds. The kinetics of excited CPT in the singlet and triplet state in the presence of halides and organics were studied in aqueous solutions at neutral $\mathrm{pH}$ by means of steady-state fluorescence and laser-flash photolysis. The fluorescence of CPT was efficiently quenched by two halides (iodide and bromide) and by four carboxylic acids (lactic, malonic, propionic and citric acid) with reaction rates close to the diffusion-controlled limit. In the triplet state, the triplet absorption spectrum was measured and its $\mathrm{pH}$ dependence was studied. The triplet state of CPT showed relatively high reactivity towards iodide, but no reaction with bromide or chloride could be observed. No singlet or triplet state quenching in the presence of limonene could be measured. A reaction mechanism is proposed, initiated by electron transfer from the quencher to the excited photosensitizer. This type of photoinduced reaction in the sea-surface microlayer has the potential to trigger the production of many oxidized species, including halogen atoms, in the bulk and gaseous phases.
\end{abstract}




\section{Introduction}

Photosensitized reactions initiated by pterin-derived compounds are involved in numerous photobiological processes. The so-called pterins are a group of heterocyclic compounds derived from 2-aminopteridin-4(3H)-one, or pterin, most commonly with a substituent at position 6 if they are unconjugated. The pterin studied herein, 6-carboxypterin (CPT), has a carboxylic functional group substituted at position 6. Pterins are widespread throughout many biological systems and play roles ranging from pigments to coenzymes, e.g. folic $\operatorname{acid}^{1}$.

Pterins have been extensively studied for their photophysical properties. In particular, their intense fluorescence has been applied for analytical purposes, for example the detection of folic acid through the fluorescence of $\mathrm{CPT}^{2}$ or, more recently, pterin-based fluorescent probes for DNA incorporation ${ }^{3,4}$. During the development of vitiligo, a human depigmentation disease of the skin, pterins including CPT are detected in the skin, indicating that excited states of pterins are generated in vivo ${ }^{5-7}$. Moreover, photosensitized reactions of some pterins can lead to DNA damage by photo-oxidation through electron transfer and/or hydrogen abstraction (type I mechanism) or through the generation of singlet oxygen (type II mechanism). The presence of CPT, produced by the photodegradation of folic acid, could play an important role in this UV-A-induced DNA damage ${ }^{8}$. Pterins not only play a role in human biology, but are thought to be chromophores in the blue-light antennas of certain higher plants ${ }^{9}$ as well as in some species of, amongst others, fungi ${ }^{10}$ and flagellates ${ }^{11}$. In the marine environment they have been detected in ascidians and their excretions ${ }^{12}$. 
Pterins are thus present in marine biology and have been identified, inter alia, to cause the enhanced UV-absorption observed in the upper layers of sea water and to induce photooxidative reactions ${ }^{13}$. Indeed, it is known that the presence of chromophores is enriched in the upper layer of the ocean, especially in the sea-surface microlayer (SML) ${ }^{14}$. The SML, defined as the organic-enriched thin interfacial layer of the sea, a few tens of micrometres in thickness, plays an important though still unclear role in air-sea chemical interactions. It is estimated, for example, that the dry deposition of ozone on the sea surface accounts for approximately one third of the global annual ozone deposition ${ }^{15,16}$. Although ozone loss is dictated by physical processes at higher wind speeds ${ }^{17}$, at low wind speed and low surface turbulence the chemical loss processes of ozone at the sea surface become dominant ${ }^{18}$. Martino and co-workers showed that both iodine and dissolved organic compounds present at the surface contributed significantly to the reactive uptake of ozone to the surface ${ }^{19}$, and other studies demonstrated the importance of ozone loss on the surface due to light-driven reactive uptake by biogenic compounds ${ }^{20}$, such as chlorophyll ${ }^{21,22}$. Halogen atoms in the gas phase, especially iodine and bromine, also strongly influence the ozone concentration in the marine boundary layer (MBL) by initiating catalytic cycles of ozone destruction ${ }^{23,24}$. These gas-phase halogen atoms can be emitted by various mechanisms, such as the photolysis of poly-halogenated compounds emitted by algae and phytoplankton ${ }^{25,26}$, the heterogeneous chemistry of ozone or $\mathrm{NO}_{\mathrm{y}}$ on snow or sea-salt particles ${ }^{27}$ and heterogeneous photochemical reactions at the sea-air interface, in particular for chlorine ${ }^{28}$. However, there still seems to be a ubiquitous missing source of iodine in the MBL, which is only partially explained by the recently proposed reaction between HOI (hypoiodous acid) and dissolved organic matter (DOM), leading to the production of volatile organoiodine compounds ${ }^{29,30}$. 
Another such source of gas-phase halogens, accounting partly for the measured halogen content, could be the photochemical oxidation of halides present in surface water or in aerosols in the $\mathrm{MBL}^{31}$. Photoactivated aromatic carbonyls, like benzophenone and imidazole-2-carboxaldehyde ${ }^{32,33}$, or biogenic compounds such as chlorophyl1 ${ }^{22}$, can lead to the formation of reactive radical anions $\left(\mathrm{X}_{2}{ }^{\cdot-}\right)$ and ultimately to the release of molecular halogens in the gas phase. Photosensitizers in the SML can thus, through their reactions with halides and ozone, influence the oxidative capacity of the MBL and contribute to the formation of aerosols. However, photosensitizers in the SML also have the capacity to react with organics, either with volatile organic compounds (VOCs) in the gas phase or with organics present in the SML or in the underlying bulk-water phase. These reactions may be favoured by the nature of the SML, where organics are concentrated at the interface, leading to the uptake of hydrophobic compounds from the gas phase, as demonstrated for the uptake of ozone by polycyclic aromatic hydrocarbons (PAHs) in the presence of an organic coating $^{34,35}$. Another indicator of photochemically active compounds in the SML is their entrainment in marine aerosols through bubble bursting and sea spray ${ }^{36-38}$. There, they can modify the composition of the particulate phase through heterogeneous reactions at the airparticle interface. Such light-induced heterogeneous reactions at the surfaces of aerosols can contribute to particle growth through the formation of low-volatility products ${ }^{39-41}$. However, little is still known about the importance of these reactions and their environmental influence.

The photosensitizer selected for this study, CPT, shows, like most unconjugated pterins, strong absorption in the UV-A, at the lower end of the actinic solar flux at sea level. Upon UV-A absorption, CPT can be excited to the short-lived singlet state, and upon 
relaxation emit a photon, measured as fluorescence. The singlet excited state of CPT $\left({ }^{1} \mathrm{CPT}\right)$ can also participate in fast reactions: (1) oxidation of DNA-specific sequences, probably through electron transfer ${ }^{8}$, and (2) oxidation through electron transfer from acetate, phosphate and iodide anions ${ }^{42,43}$. The calculated quantum yield of fluorescence of CPT is 0.18 in basic medium and 0.28 in acidic medium, with an estimated energy of $2.87-2.90$ $\mathrm{eV}^{44,45}$. However, CPT can also form a longer-lived triplet state upon excitation. Triplet excited state CPT $\left({ }^{3} \mathrm{CPT}\right)$ can also participate in photosensitized reactions, as reported for the degradation of a nucleotide (dGMP) through type I (electron transfer) and type II mechanisms ${ }^{46}$. Unlike ${ }^{1} \mathrm{CPT},{ }^{3} \mathrm{CPT}$ is an efficient photosensitizer for singlet oxygen and also plays a role in $\mathrm{O}_{2}\left({ }^{1} \Delta \mathrm{g}\right)$-mediated reactions (type II mechanism) ${ }^{44}$. In this last study, the authors estimated the energy of the triplet state of CPT at $2.45 \mathrm{eV}$.

In the present work, light-induced reactions between a naturally occurring photosensitizer, 6-carboxypterin, and three common sea salts, $\mathrm{NaI}, \mathrm{NaBr}$ and $\mathrm{NaCl}$, in aqueous solutions are studied. The reaction of CPT with four small organic acids and a monoterpene, limonene, is also examined. The small carboxylic acids studied here (lactic, propionic, malonic and citric acid) represent the small carboxylic acids ubiquitously present in the atmosphere, including in aerosols ${ }^{47}$. In the MBL these acids have been related to biological activity and measured in the gas and particulate phases ${ }^{48}$. Limonene is a model compound for biogenic VOCs and a known hydrogen donor in photosensitized reactions ${ }^{41}$. The reaction kinetics were determined by laser-flash photolysis and fluorimetry, and additional analysis of the oxidation products of the organics was performed by ultrahighperformance liquid chromatography-high-resolution mass spectrometry (UPLC-HRMS). 


\section{Experimental}

\section{Chemicals}

Malonic acid (99\%), citric acid (99\%) and limonene ((R)-(+)-limonene, 97\%) were provided by Sigma-Aldrich, propionic acid ( $\geq 99.5 \%)$, lactic acid $(90 \%)$ and O- $(2,3,4,5,6-$ pentafluorophenyl)methylhydroxylamine (PFBHA, $\geq 99.0 \%$ ) by Fluka. 6-Carboxypterin (pterin-6-carboxylic acid, > 97.5\%) was purchased from Schircks Laboratories (Jona, Switzerland). Acetonitrile (HPLC-MS Optima grade, Fisher Scientific, France) was used for mass spectrometric analysis. All chemicals were used as purchased without further purification. Solutions were freshly prepared in 18-M $\Omega$ ultrapure water (Elga); 10 minutes of sonication was needed to obtain complete dissolution of CPT. The solutions containing limonene were prepared in a water/acetonitrile mixture $(1: 1, \mathrm{v} / \mathrm{v}$, Elga ultrapure water, France/HPLC-MS Optima grade, Fisher Scientific, France). A 1-M solution of sodium hydroxide $(\mathrm{NaOH}, \geq 98 \%$ reagent grade, Sigma-Aldrich) was added dropwise to the solutions to obtain the desired $\mathrm{pH}$. Fluorescence and laser-flash photolysis experiments were performed at $\mathrm{pH}=7-7.3$ and verified with a $\mathrm{pH}$ meter $(\mathrm{pH} 100, \mathrm{VWR})$. At this $\mathrm{pH}$, propionic acid and lactic acid are in their carboxylate forms. Citric acid and malonic acid are almost entirely, $>95 \%$, in their completely deprotonated forms. CPT, which has a $\mathrm{p} K_{\mathrm{a}}$ of 7.9 on the pterin ring, is mainly in its carboxylate mono-anionic form as shown in the inset of Fig. 1. The UV-Vis absorption spectrum taken at different $\mathrm{pH}$ shows two maxima (Fig. S1 and Table S1, ESI $\dagger$ ), with a shift towards longer wavelengths in more alkaline conditions accompanied by an increase of the molar absorption coefficient. One could argue in light of Fig. S1 that more basic conditions enhance the absorption of the lower-energy absorption peak and emphasize the peak shift towards the longer wavelengths. However, 
several reasons motivated the choice of a more neutral $\mathrm{pH}$ : (1) reactions at a more neutral $\mathrm{pH}$ are more environmentally relevant; (2) if the studied reaction involves electron transfer from e.g. a halide $\mathrm{X}^{-}$to ${ }^{3} \mathrm{CPT}$, then this reaction might be favoured in the presence of the mono-anionic form of ${ }^{3} \mathrm{CPT}$; and (3) precautions at high alkalinity must be taken, since $\mathrm{OH}^{-}$ quenching of the singlet excited state has been shown ${ }^{45}$. UV-Vis absorption spectra of the prepared solutions were taken with an Agilent $8453 \mathrm{UV}-\mathrm{Vis}$ spectrometer in $1 \mathrm{~cm}$ quartz cuvettes. All experiments were performed at room temperature.

\section{Laser-flash photolysis}

The transient absorption spectrum of the excited CPT was measured with a classical laserflash photolysis (LFP) apparatus ${ }^{32}$. The photolysis excitation source was the second harmonic (355 nm, pulse width $\left.\pm 7 \times 10^{-9} \mathrm{~s}\right)$ of a Nd:YAG laser (Surelite II 10, Continuum, U.S.) operated in the single-shot mode. At $\mathrm{pH}=7.4$ the UV-Vis absorption spectrum of CPT shows two maxima, one around $285 \mathrm{~nm}$ and the other around $347 \mathrm{~nm}$ (Fig. 1). The excitation wavelength was chosen at the most environmentally relevant absorption maximum. During the experiments, the laser pulse energy was limited to $45 \mathrm{~mJ} / \mathrm{pulse}( \pm$ $159 \mathrm{~mJ} / \mathrm{cm}^{2}$ ) to limit as much as possible the photolysis of the photosensitizer and therefore the possible interference of its products on the studied chemistry. The working solutions containing $0.2 \mathrm{mM} \mathrm{CPT}$ were deoxygenated by $\mathrm{N}_{2}$ bubbling for at least $30 \mathrm{~min}$ before the start of the experiment and continuously kept under $\mathrm{N}_{2}$ flow during the experiment. Transient species produced by the pulsed laser beam were monitored by means of timeresolved absorption spectroscopy. The analysing light, provided by a $75 \mathrm{~W}$ high-pressure Xe arc lamp (LOT-Oriel), passed through the two apertures of the long axis of the flow cell 
(1 cm path length). The light was then collected by a $1 / 4-\mathrm{m}$ monochromator (Spectral Products DK240) equipped with a 2400 grooves/mm grating and detected by a photomultiplier (Hamamatsu H7732-01). The photo-multiplier signal was passed through a highspeed current amplifier/discriminator (Femto) and the AC component recorded on a 300 MHz oscilloscope (Tektronix TDS3032c). The digitalized signal was then transferred to a computer for further processing. To construct the absorption spectrum, measurements were repeated every 5-20 nm between $380 \mathrm{~nm}$ and $700 \mathrm{~nm}$, limits determined by the LFP apparatus and the absorption of ${ }^{3} \mathrm{CPT}$. For the kinetic measurements, the probe wavelengths for the transient absorption decay of the triplet state of CPT were 400 and $425 \mathrm{~nm}$, the two maxima in the triplet state absorption spectra. Further details on the setup and signal treatment are available in the supplementary material (ESI $\dagger$ ).

\section{Steady-state fluorescence}

Steady-state fluorescence was performed using a commercial fluorimeter (Perkin Elmer). Solutions containing $0.1 \mu \mathrm{M} \mathrm{CPT}$ were $\mathrm{pH}$-adjusted and introduced into a quartz cell (path length $1 \mathrm{~cm}$ ) without deoxygenation. The excitation wavelength was set at $350 \mathrm{~nm}$ and emission spectra were registered between $360 \mathrm{~nm}$ and $540 \mathrm{~nm}$. The absorbance of the solutions at the excitation wavelength was kept below 0.1 , to keep the irradiance homogeneous within the cuvette. The emission spectrum showed a maximum at $438 \mathrm{~nm}$ at $\mathrm{pH}=7.2$, in good agreement with the literature values for the acidic, mono-anionic form of $\mathrm{CPT}^{45}$, while the basic, di-anionic form of CPT has an emission maximum at $451 \mathrm{~nm}^{45}$. In our spectra no shoulder or specific peak broadening was observed at this wavelength; however, it must be kept in mind that the di-anionic form of CPT accounts for 9-28.5\% of 
the emission spectrum, depending on the $\mathrm{pH}$ of the solution (for more details see ESI $\dagger$ ). Regular control measurements of pure water were performed and the spectra were blankcorrected.

\section{Chemical analysis}

Analysis of the oxidation products of the organics was performed using ultrahighperformance liquid chromatography coupled with heated electrospray ionization (HESI; positive and negative modes) and high-resolution mass spectrometry (UPLC-HRMS). A $500 \mu \mathrm{L}$ aliquot of each sample was diluted in $500 \mu \mathrm{L}$ of a $1: 1(\mathrm{v} / \mathrm{v})$ water/acetonitrile mixture. Additionally, $200 \mu \mathrm{L}$ of each sample was diluted in $800 \mu \mathrm{L}$ of a $1 \mathrm{mg} \mathrm{mL}^{-1} \mathrm{O}-$ (2,3,4,5,6-pentafluorophenyl)methylhydroxylamine hydrochloride solution (prepared daily from PFBHA, $\geq 99.0 \%$, Fluka, dissolved in a 1:1 (v/v) water/acetonitrile mixture) and left at room temperature for 24 hours to complete the selective derivatization of the carbonyl groups. These two dilutions were performed in triplicate for each sample (two samples per experiment, before and after irradiation). A Dionex Ultimate 3000 (UPLC, Thermo Scientific, U.S.) was equipped with an HSS T3 Acquity UPLC column $(1.8 \mu \mathrm{m}, 2.1 \times 100$ $\mathrm{mm}$ ). The mobile phase was (A) acidified water (HPLC-MS Optima grade, Fisher Scientific, France $+0.1 \%$ (v/v) formic acid, HPLC-MS Optima grade, Fisher Scientific, France) and (B) acidified acetonitrile (HPLC-MS Optima grade, Fisher Scientific, France, $+0.1 \%(\mathrm{v} / \mathrm{v})$ formic acid, HPLC-MS Optima grade, Fisher Scientific, France). A 22 min gradient was applied at a constant flow rate of $0.3 \mathrm{~mL} \min ^{-1}$ : eluent (B) was kept at $1 \%$ for $2 \mathrm{~min}$, then increased to $100 \%$ in $11 \mathrm{~min}$ and kept at $100 \%$ for $2 \mathrm{~min}$; the system was then returned to initial conditions, $1 \%$ of $(\mathrm{B})$, in $0.1 \mathrm{~min}$ and was left to stabilize for $7 \mathrm{~min}$. The 
injection volume of the non-derivatized diluted samples was $5 \mu \mathrm{L}$ and the injection volume of the PFBHA-derivatized samples was $10 \mu \mathrm{L}$. HESI voltages of $+3.7 \mathrm{kV}$ and $-3.0 \mathrm{kV}$ were applied for the positive $(+)$ and negative (-) ionization modes, respectively. All the HRMS acquisitions were performed in full MS mode with the scan ranging from $\mathrm{m} / \mathrm{z}=50$ to $\mathrm{m} / \mathrm{z}$ $=750$ and the resolution set to 140,000 . Further details on blanks and signal stability can be found in the supplementary material (ESI $\dagger)$.

\section{Results and discussion}

\section{Singlet state reactivity}

The reactivity of ${ }^{1} \mathrm{CPT}$ with halides and five different organics was measured by steady-state fluorescence. For each quencher added, UV-Vis absorption spectra were first taken of a nonirradiated solution to assure that the quenching observed was not due to changes in the absorption spectrum of the ground state. The absorption spectrum and emission spectrum of an aqueous solution of $\mathrm{CPT}$ at $\mathrm{pH}=7$ are shown in Fig. 1 . If a reaction between ${ }^{1} \mathrm{CPT}$ and the quencher occurs, a fraction of the ${ }^{1} \mathrm{CPT}$ will be deactivated by interaction with the quencher and thus the relative intensity of the fluorescence emission will decrease.

Fig. 2 shows the fluorescence emission spectra of a solution of CPT in the presence of different concentrations of $\mathrm{NaBr}$. An increase in the concentration of $\mathrm{NaBr}$ leads to a clear decrease in the fluorescence intensity, revealing that bromide ions effectively quench ${ }^{1} \mathrm{CPT}$. Similar results were obtained for the other quenchers, except for chloride and limonene (see Fig. S2 (a)-(g), ESI†). 
An increase in the concentration of chloride or limonene does not lead to a clear decrease in the fluorescence intensity, and therefore no evidence was found for the reaction of these species with ${ }^{1} \mathrm{CPT}$. The dynamic quenching rates were then determined for each efficient quencher using the Stern-Volmer equation (Eq. 1):

$$
\frac{I_{0}}{I}=1+k_{Q} \tau_{F}[Q]
$$

where $I_{0}$ is the fluorescence intensity without a quencher, $I$ the intensity in the presence of a quencher, $k_{\mathrm{Q}}$ the bi-molecular rate coefficient $\left(\mathrm{M}^{-1} \mathrm{~L}^{-1}\right), \tau_{\mathrm{F}}$ the fluorescence lifetime in the absence of a quencher and [Q] the concentration of the quencher in $\mathrm{M}$.

The fluorescent lifetime of CPT was determined with the laser-flash photolysis set-up used for the transient study of triplet state reactivity. By exciting an aqueous solution of $\mathrm{CPT}$ at $\mathrm{pH}=$ 7.3 with a laser pulse $(355 \mathrm{~nm})$, a transient fluorescent signal was measured. This signal was well fitted with a simple mono-exponential function (Eq. 2),

$$
y=a+b e^{-t k}
$$

where $a$ is the offset, $b$ is the initial value, $t$ is time (s) and $k$ is the decay rate $\left(\mathrm{s}^{-1}\right)$. The lifetime of the singlet state was calculated as

$$
\tau_{F}=\frac{1}{k}
$$


From our measurements, the fluorescence lifetime is determined to be $\tau_{\mathrm{F}}(440 \mathrm{~nm})=(4.9 \pm 0.2) \times$ $10^{-9} \mathrm{~s}$. This is in good agreement with the lifetime of $4.6 \times 10^{-9} \mathrm{~s}$ reported by Swarna et al. ${ }^{43}$ for ${ }^{1} \mathrm{CPT}$ in a buffered solution at $\mathrm{pH}=7.3$.

From the Stern-Volmer plots for the different quenchers, Figs. 3 (a) and (b), it can be seen that all quenchers except chloride show linear behaviour, indicating a dynamic quenching reaction. For clarity, limonene is not included in the plots (vide infra). Iodide is the most efficient quencher of all those tested, and citric acid and malonic acid are the most efficient organic quenchers. From the slopes obtained by the linear fits, the bi-molecular rate coefficients were determined and are given in Table 1. The uncertainties indicated represent the uncertainties of the linear fitting procedures, calculated as three times the standard deviation of the slope. The adjusted linear determination coefficient $\mathrm{R}^{2}$ is also given as an indication of the goodness of the fit. The bi-molecular rate coefficients are quite similar for all the quenchers and are close to the diffusion-controlled limit for aqueous solutions. As indicated in Table 1, the bi-molecular rate coefficient for iodide obtained in this study is somewhat smaller than the one reported in the literature ${ }^{43}$ at $\mathrm{pH}=7.3$, but quite comparable.

Quenching by electron transfer from the quencher to the excited photosensitizer was very efficient for iodide and bromide, but for chloride no quenching was observed. This is confirmed by the free energies calculated with the Rehm-Weller equation (4), which estimates the free energy change $\Delta G$ for the proposed electron transfer in polar solvents:

$$
\Delta G(e V)=\left[E_{o x}(D)-E_{r e d}(A)-C\right]-\Delta E_{0,0}
$$


where $E_{\mathrm{ox}}(\mathrm{D})$ and $E_{\text {red }}(\mathrm{A})$ are the redox potentials of the electron donor (D) and acceptor (A), respectively. The oxidation potential of the electron donor $E_{\mathrm{ox}}(\mathrm{D})$ corresponds to the oxidation potentials of the halide anions $\mathrm{X}^{-}$, which are listed in Table $2^{49}$. The values for the redox potential of CPT were taken as $E_{\text {red }}(\mathrm{A})=-0.6 \mathrm{~V}^{50}$ and $E_{\text {red }}(\mathrm{A})=-0.73 \mathrm{~V}^{51}$. Both were used in Eq. 4 , and the results were taken as the upper and lower limits for $\Delta G . E_{0,0}$ is the energy of the lowest-lying singlet state of CPT and can be determined from the absorption and fluorescence emission spectra. For $\mathrm{CPT}$ this quantity has been estimated at $2.87 \mathrm{eV}^{44}$. $C$ is the Coulomb term expressing the solvation energy of an ion pair $\mathrm{D}+\mathrm{A}$, and can be ignored in polar solvents. Electron transfer from the quencher to the excited photosensitizer can only take place if the free energy $\Delta G$ of this process is negative (or very close to zero) ${ }^{32}$.

For chloride, Eq. 4 yields $\Delta G=0.33 / 0.46 \mathrm{eV}$, which indicates that electron transfer is indeed thermodynamically unfavourable. As shown in Table 1, the free energies $\Delta G$ for electron transfer from iodide and bromide are slightly negative, which confirms that electron transfer in this case is thermodynamically favourable. The reactivity towards the deprotonated carboxylic acids is highest for malonic acid and citric acid, both of which have multiple carboxylic groups and thus multiple negative charges at this $\mathrm{pH}$. This strongly suggests that electron transfer to ${ }^{1} \mathrm{CPT}$ is also a possible quenching mechanism for these species. If hydrogen transfer were driving the observed quenching, then the conjugated acids, citric and lactic acid, would be expected to be the most reactive compounds. Indeed, as the $\mathrm{C}-\mathrm{H}$ bond of conjugated carbons is less energetic, the reaction would be favoured by the presence of hydroxyl groups on the carbon chain, since the formed ${ }^{\circ} \mathrm{C}$ $\mathrm{OH}$ radical would be stabilized through the captodative effect $^{52}$. Although citric acid is the most reactive organic quencher, lactic acid shows the lowest reactivity, which is not consistent with a hypothetical hydrogen transfer mechanism. If the quenching rate coefficients are divided by the 
number of carboxylic groups, and thus the number of easily available electrons, as shown in the third column of Table 1, all carboxylic acids show very similar rate coefficients, around $1 \times 10^{9}$ $\mathrm{M}^{-1} \mathrm{~s}^{-1}$, supporting the hypothesis that electron transfer from the carboxylate groups to ${ }^{1} \mathrm{CPT}$ is the mechanism behind the observed quenching.

In the case of limonene as quencher, no clear trend in the fluorescence intensity can be seen (Fig. S2 (g), ESI $\dagger$ ). In order to solubilize limonene, a mixture of acetonitrile and water (50:50, v/v) was used as solvent. The absorption spectrum of CPT in the presence of $30 \mathrm{mM}$ limonene does not provide evidence for any ground state changes, although the overall absorption is somewhat higher $(\sim 10 \%)$. However, in the acetonitrile/water mixture, the fluorescence is around $60 \%$ lower than in the case of the pure water solvent. The effect of binary mixtures on the spectroscopic characteristics of a solute is very complex and therefore difficult to predict. The observed effect could be due to specific solvation of $\mathrm{CPT}$ in the acetonitrile/water mixture, to changes in the polarity, and/or to changes in the hydrogen bonding of this solvent mixture ${ }^{53,54}$.

\section{Triplet state reactivity}

CPT triplet state in water at neutral $\mathbf{p H}$. Triplet excited states are often considered the most reactive excited states in photochemistry, due to their longer lifetimes and ability to form singlet oxygen in the presence of molecular oxygen. Laser-flash photolysis of CPT in deoxygenated aqueous solutions showed the absorption of a rather long-lived transient species, attributed to the triplet state of CPT. Fig. 4 shows the absorption spectrum of the triplet state at different time intervals after the laser pulse. The absorption spectrum shows a peak maximum at 400-430 nm, a 
broad absorption band around $500-550 \mathrm{~nm}$ and a peak at $650 \mathrm{~nm}$. The wavelengths for the absorption maxima correspond quite well with the maxima previously reported for ${ }^{3} \mathrm{CPT}$ absorption in DMSO, but the DMSO spectrum did not show a maximum at $650 \mathrm{~nm}^{51}$. The spectra at $1 \times 10^{-6}$ $\mathrm{s}$ and $8 \times 10^{-6} \mathrm{~s}$ after the laser pulse demonstrate a rather uniform decrease of the absorbance, without the formation of any significant band. These spectra provide no evidence for the existence of transient species, as previously proposed for the increased absorption of pterin at $480 \mathrm{~nm}$ and CPT at $390 \mathrm{~nm}$ in DMSO, which were attributed to the formation of a semi-reduced pterin radical ${ }^{51}$, 55.

To determine the lifetime and reactivity, the triplet state decay was monitored at two wavelengths, i.e. $400 \mathrm{~nm}$ and $425 \mathrm{~nm}$, in the first broad maximum absorption peak, since our laserflash photolysis system is most accurate in that region. The ${ }^{3} \mathrm{CPT}$ lifetime can be determined from the decay curves of the triplet state absorption, by fitting these curves with an exponential function. For pterin, the non-substituted form of CPT, a bi-exponential decay of the triplet state has previously been revealed through dual phosphorescence, and was explained by the co-existence of lactim and lactam tautomers in the triplet excited state ${ }^{55,56}$. Although in the ground state one tautomer, the lactam form, is expected to be dominant, upon excitation, a fast intramolecular proton transfer produces two tautomeric forms in the triplet state. However, recent calculations have shown that the most probable tautomers for pterin and 6-methylpterin in aqueous solutions were the lactam and $1(H)$-lactam tautomers rather than the lactim tautomer ${ }^{57,58}$. By analogy, and considering the very similar structures, the same tautomers, shown in Fig. S3 (ESI $\dagger$ ), can be expected to be stable for excited CPT, and hence a bi-exponential decay rate of the triplet state can be presumed. The ${ }^{3} \mathrm{CPT}$ decay curve is indeed well fitted by the following bi-exponential function: 


$$
\mathrm{y}=\mathrm{a}+\mathrm{b} e^{\left(-t k_{1}\right)}+c e^{\left(-t k_{2}\right)}
$$

The obtained decay rates, $k_{1}$ and $k_{2}$, for the triplet-triplet absorption curve monitored at $425 \mathrm{~nm}$ are $(1.66 \pm 0.27) \times 10^{6} \mathrm{~s}^{-1}$ and $(3.70 \pm 0.05) \times 10^{5} \mathrm{~s}^{-1}$, corresponding to triplet lifetimes of $0.6 \times 10^{-6}$ $\mathrm{s}$ and $2.7 \times 10^{-6} \mathrm{~s}$. These lifetimes are appreciably shorter than the lifetimes of ${ }^{3} \mathrm{CPT}$ in DMSO, $1.1 \times 10^{-6}$ and $9.1 \times 10^{-6} \mathrm{~s}^{51}$, but are comparable to the lifetimes obtained for aqueous solutions of triplet state biopterin, $0.3 \times 10^{-6}$ and $2.0 \times 10^{-6} \mathrm{~s}^{56}$, and for triplet state pterin itself, i.e. $0.3 \times 10^{-6}$ and $2.3 \times 10^{-6} \mathrm{~s}^{55}$.

Influence of pH on the triplet state absorption. The influence of the $\mathrm{pH}$ on the ground state CPT is clearly shown in Fig. S1 (ESI $†$ ), and the influence of the $\mathrm{pH}$ on the fluorescence was reported previously $\mathrm{y}^{45,59}$. For pterin and pterin derivatives, an influence of the $\mathrm{pH}$ on the triplet state has also been observed ${ }^{44,55}$. We therefore decided to investigate the influence of the $\mathrm{pH}$ on the triplet-triplet state absorption. The differential transient absorption spectra of ${ }^{3} \mathrm{CPT}$ recorded by LFP at four different $\mathrm{pH}$ values $(6.1,7.3,8.2$ and 10.8$)$ are compared in Fig. $5 .{ }^{3} \mathrm{CPT}$ absorbs more strongly at alkaline $\mathrm{pH}$, with the maximum absorption at $\mathrm{pH}=8.2$. All spectra show a broad, ill-defined absorption band around $550 \mathrm{~nm}$, and another broad absorption band around 400-430 nm, composed of two peaks centred at $400-410 \mathrm{~nm}$ and $425-440 \mathrm{~nm}$. Both peaks around $410 \mathrm{~nm}$ and $430 \mathrm{~nm}$ are present for all $\mathrm{pH}$ conditions, meaning they cannot be attributed distinctively to the protonated mono-anionic $\mathrm{CPT}$ or deprotonated di-anionic $\mathrm{CPT}$, since at $\mathrm{pH}=6.1$ only the mono-anionic form of CPT is present $\left(\mathrm{p} K_{\mathrm{a}}=7.9\right)$ and at $\mathrm{pH}=10.8$ only the di-anionic form is present. This supports the hypothesis that different tautomers of CPT contribute to the absorption in these absorption bands, resulting in bi-exponential decay behaviour. At all $\mathrm{pH}$ values, the decay rates are best described by a bi-exponential equation at $440 \mathrm{~nm}$, with lifetimes in the $\mathrm{pH}$ range $6-9$ of $\tau_{\mathrm{T} 1}=0.45-$ 
$0.60 \times 10^{-6} \mathrm{~s}$ for the short-lived and $\tau_{\mathrm{T} 2}=2.5-3.5 \times 10^{-6} \mathrm{~s}$ for the long-lived component. Interestingly, a clear decrease in the triplet lifetime is seen at $\mathrm{pH}=10.8$, giving lifetimes of $\tau_{\mathrm{T} 1}=$ $(0.81 \pm 0.04) \times 10^{-6} \mathrm{~s}$ and $\tau_{\mathrm{T} 2}=(0.29 \pm 0.04) \times 10^{-6} \mathrm{~s}$, when fitting the decay rate of the absorption at $440 \mathrm{~nm}$. By analogy with a similar feature observed for triplet state pterin, this can tentatively be explained by the deprotonation of the triplet state leading to a dissociation constant for the triplet state that is substantially higher, $\mathrm{p} K_{\mathrm{aT}}{ }^{*}>9$, than for ground state $\mathrm{CPT}^{55}$. However, contrary to the pterin absorption spectrum, CPT does not show very distinctive absorption for the deprotonated species at this $\mathrm{pH}$, apart from a peak broadening around $440 \mathrm{~nm}$. At this point, it remains difficult to attribute with certainty the higher triplet absorption decay rate at $\mathrm{pH}=10.8$ to the deprotonated triplet form. Other factors that could contribute to higher decay rates are $\mathrm{OH}^{-}$ quenching and the formation of different stable tautomers at $\mathrm{pH}>9$, but addressing these intriguing issues lies beyond the scope of this work.

Quenching of the triplet state. The reactivity of ${ }^{3} \mathrm{CPT}$ with halides is interesting, since the triplet state has a lifetime three orders of magnitude higher than the singlet state. As the reaction between singlet state CPT and some halides, notably $\mathrm{I}^{-}$and $\mathrm{Br}^{-}$, is not negligible, the maximum ${ }^{3} \mathrm{CPT}$ absorption would be expected to decrease in the presence of increasing concentrations of halides, since a fraction of the singlet state CPT would be deactivated by the reaction with the quencher. However, for constant concentrations of CPT under the same conditions, this deactivation should not influence the decay rate of the triplet state absorption. The reaction with halides was tested at neutral $\mathrm{pH}$ (7-7.5) by introducing increasing concentrations of a quencher into deoxygenated solutions of CPT, with a large excess of the quencher with respect to CPT in order to maintain pseudo-first-order conditions. The decay of the triplet state absorption was monitored at the 
maximum absorption wavelengths at this $\mathrm{pH}$ range, in the range of $400-430 \mathrm{~nm}$ with maxima at $400 \mathrm{~nm}$ and $425 \mathrm{~nm}$. As demonstrated above, evidence for the presence of two tautomeric forms of the photosensitizer explains the bi-exponential decay of ${ }^{3} \mathrm{CPT}$ absorption at $425 \mathrm{~nm}$. Surprisingly, the decay rate at $400 \mathrm{~nm}$ was best fitted with a mono-exponential function. This different behaviour became even clearer upon the addition of halides. A clear difference can be seen in Fig. 6 between the signal registered at $400 \mathrm{~nm}$ (Fig. 6 (a)) and the signal at $425 \mathrm{~nm}$ (Fig. 6 (b)) in the presence of $10 \mathrm{mM}$ of NaI. The decay rate obtained by fitting the signals registered at $400 \mathrm{~nm}$ was very similar to that for the longer-lifetime component of the bi-exponential fits at 425 $\mathrm{nm}$, in the absence of a quencher. This leads to the conclusion that the tautomer absorbing at 400 $\mathrm{nm}$ still shows some absorption at $425 \mathrm{~nm}$, overlapping with the second tautomer with a shorter lifetime. As becomes clear from Fig. 6 (a), the tautomer absorbing at $400 \mathrm{~nm}$ shows no measurable reaction with $\mathrm{I}^{-}$, and the same is true for $\mathrm{Br}^{-}$and $\mathrm{Cl}^{-}$. Similar differences in kinetics between different tautomers of the triplet state of a pterin derivative have been observed in reaction with an organic $^{46}$. The decay rate obtained at $400 \mathrm{~nm}$ can then be used to restrain the value of $k_{2}$ in Eq. (5) to obtain the decay rate $k_{1}$ of the second tautomer in the signals recorded at $425 \mathrm{~nm}$ in the presence of a quencher. The quenching rate for the second tautomer can then be determined by the SternVolmer equation (6), using the $k_{1}$ decay rates obtained at $425 \mathrm{~nm}$ with different concentrations of the quencher:

$$
\frac{d\left[{ }^{3} C P T\right]}{d t}=\left(k_{1,0}+k_{1, Q}[Q]\right)\left[{ }^{3} C P T\right]=k_{1, o b s}\left[{ }^{3} C P T\right]
$$

where $k_{1,0}$ is the decay rate of the short-lived component $k_{1}$ at $425 \mathrm{~nm}$ without a quencher and $k_{1, \mathrm{Q}}$ the bi-molecular rate coefficient for the quenching process in the presence of a 
quencher Q. The slope of the linear fits of $k_{1 \text {,obs }}$ as a function of [Q] on the Stern-Volmer plot gives the quenching rate coefficient $k_{1, \mathrm{Q}}$ for the short-lived tautomer.

By proceeding this way, the bi-molecular quenching coefficients for the three halides were determined, as shown in Fig. 7. For iodide, a clear quenching of ${ }^{3} \mathrm{CPT}$ was revealed, as expressed by the rather high reaction coefficient, $(1.89 \pm 0.22) \times 10^{8} \mathrm{M}^{-1} \mathrm{~s}^{-1}$ (Table 2). This rate coefficient is an order of magnitude lower than the reaction rate of ${ }^{1} \mathrm{CPT}$ with iodide, but as the triplet state is three orders of magnitude longer lived than the singlet one, its reactivity will nonetheless play a prominent role in the reaction with iodide.

The quenching rate coefficients of ${ }^{3} \mathrm{CPT}$ with bromide and chloride are much lower, respectively $(2.99 \pm 0.76) \times 10^{6}$ and $(2.25 \pm 1.83) \times 10^{6} \mathrm{M}^{-1} \mathrm{~s}^{-1}$, and almost no increase in the decay rates was observed, even with concentrations of halides added up to $0.2 \mathrm{M}$. Higher concentrations of these halides $(>0.25 \mathrm{M})$ even led to slightly longer lifetimes, which could be due to the change in ionic strength of the solution or to the heavy-atom effect ${ }^{60}$. These points were not taken into account in the Stern-Volmer plot, as they clearly did not show linear dependence. Although almost no reaction was observed with bromide and chloride, the quenching with iodide was quite fast, suggesting an electron transfer mechanism. Indeed, as iodide has the lowest oxidation potential of the halides tested (Table 2), therefore representing the best electron donor, it is not surprising that the highest rate coefficient was observed for quenching with this anion. Electron transfer from bromide and chloride seems to be thermodynamically unfavourable, as reflected by the very low rate coefficients. This is confirmed by the free energy change of the proposed electron transfer reaction estimated by the Rehm-Weller equation (4), with $E_{0,0}$ in this case being the energy of the lowest-lying triplet state of CPT. This lowest triplet energy level can 
be obtained from the phosphorescence spectra, and the values reported in the literature are 2.52 $\mathrm{eV}^{51}$ and $2.45 \mathrm{eV}^{44}$. In Table 2 the calculated values of $\Delta G$ are given for each halide, with an upper and lower limit using the different reported values of $E_{\mathrm{T} 0,0}$ and $E_{\mathrm{ox}}(\mathrm{D})$.

As is clear from the values of $\Delta G$, electron transfer is only thermodynamically favourable in the case of iodide. The positive values of the free energy in the case of bromide and chloride indicate that electron transfer from these halides to the triplet state is not thermodynamically favourable, which explains the very low reaction rates observed.

The quenching of ${ }^{3} \mathrm{CPT}$ by limonene was also investigated, where proton transfer from limonene to ${ }^{3} \mathrm{CPT}$ might occur, as has been found for other photosensitizers ${ }^{41}$. The solvent used here was a mixture of acetonitrile and water, as for the fluorescence measurements, in order to solubilize limonene. The $\mathrm{pH}$ was also adjusted to equivalent values as for the fluorescence measurements. At $\mathrm{pH}=7.3$ the transient absorbance signal was too low to be analysed, while at $\mathrm{pH}=10.6$ the solution showed a higher absorbance. The deprotonated di-anionic form of CPT, prevalent at this $\mathrm{pH}$, was considered a candidate hydrogen acceptor. At $\mathrm{pH}=10.6$ the transient signals obtained with laser-flash photolysis showed clear mono-exponential absorbance by the triplet state. The ${ }^{3} \mathrm{CPT}$ decay rate determined at $425 \mathrm{~nm}$ was $(6.11 \pm 0.04) \times 10^{5} \mathrm{~s}^{-1}$, meaning that the triplet lifetime of $1.64 \times 10^{-6} \mathrm{~s}$ under these conditions is comparable with but smaller than that of the longer-lived tautomer, $\tau_{T}=2.7 \times 10^{-6} \mathrm{~s}$, in water at neutral $\mathrm{pH}$. The mono-exponential decay indicates that in the acetonitrile/water mixture at this equivalent $\mathrm{pH}$, no tautomerization takes place in the triplet state. The mechanisms proposed to explain the tautomerization of pterins involve strong interactions with water, which either promotes intramolecular proton shift as a solvent or is directly involved in intermolecular proton exchange as a reactant ${ }^{61}$. As acetonitrile is an aprotic 
solvent, these hydrogen-bonding effects could be largely suppressed, explaining the presence of a single tautomer of CPT and hence the mono-exponential decay rate. Upon the addition of limonene to the CPT solution, no quenching was observed, as shown in Fig. S4 (ESI $\dagger$ ), though a slight decrease in the overall absorption was noted in the presence of $100 \mathrm{mM}$ of limonene.

\section{Excited state reactivity: mechanism and product formation}

The mechanism involved in all the quenching processes studied in this work is electron transfer between the quencher and the excited CPT. Electron transfer to the singlet state is more efficient, as the singlet state is more energetic and has a higher quantum yield than the triplet state. The less energetic ${ }^{3} \mathrm{CPT}$ only shows efficient quenching by electron transfer from iodide. The following general mechanism can thus be proposed for the photo-induced reactions between excited CPT and small carboxylic acids:

$$
\begin{aligned}
& { }^{1} \mathrm{CPT}+\mathrm{Q} \rightarrow \mathrm{CPT}^{--}+\mathrm{Q}^{+} \\
& \mathrm{Q}^{\cdot+}+\mathrm{CPT} \rightarrow \text { products } \\
& \mathrm{CPT}^{--}+\mathrm{CPT} \rightarrow \text { products }
\end{aligned}
$$

For the halides, these reactions give rise to the formation of atomic halogens $\left(\mathrm{X}^{\circ}\right)$, which, in the presence of an excess of the halide anion $\left(\mathrm{X}^{-}\right)$, can recombine and form radical anions $\left(\mathrm{X}_{2}{ }^{--}\right)$, as shown in the following reaction mechanism. The triplet state CPT only reacts with iodide.

$$
{ }^{1} \mathrm{CPT}+\mathrm{X}^{-} \rightarrow \mathrm{CPT}^{\cdot-}+\mathrm{X}^{\cdot}
$$




$$
\begin{aligned}
& { }^{1} \mathrm{CPT} \longrightarrow{ }^{3} \mathrm{CPT} \\
& { }^{3} \mathrm{CPT}+\mathrm{X}^{-} \rightarrow \mathrm{CPT}^{\cdot-}+\mathrm{X}^{\cdot} \\
& \mathrm{X}^{\cdot}+\mathrm{X}^{-} \rightleftarrows \mathrm{X}_{2}^{\cdot-} \\
& \mathrm{X}^{\cdot}+\mathrm{CPT} \rightarrow \text { products } \\
& \mathrm{X}_{2}^{\cdot-}+\mathrm{CPT} \rightarrow \text { products } \\
& \mathrm{X}^{\cdot}+\mathrm{X}^{\cdot} \rightarrow \mathrm{X}_{2} \\
& \mathrm{X}_{2}{ }^{--}+\mathrm{X}_{2}{ }^{--} \rightarrow \mathrm{X}_{2}+2 \mathrm{X}^{-} \\
& \mathrm{X}_{2} \rightleftarrows \mathrm{X}_{2}(\mathrm{~g})
\end{aligned}
$$

Both the atomic halogen radical and the radical anion $\mathrm{X}_{2}{ }^{--}$are strong oxidants and can react with the photosensitizer or other organic compounds present (R9 \& 10). If sufficient radical anions $\mathrm{X}_{2}{ }^{--}$ are formed, the recombination of two radicals (R11) can lead to the release of molecular halogens in the gas phase (R12).

UPLC-HRMS analysis of irradiated solutions containing CPT and lactic acid or limonene showed the formation of products consistent with electron transfer as proposed above. A list of products observed with limonene and lactic acid is presented in Table 3. For limonene, several products showed different chromatographic peaks, probably due to the presence of different isomers. In view of these results, a formation mechanism is proposed in Fig. 8 (a) and (b) for the reactions of CPT with lactic acid and limonene, respectively, both initiated by electron transfer leading to the formation of an alkyl radical. Fig. 8 (a) details the formation of the observed product glyceric acid $\left(\mathrm{C}_{3} \mathrm{H}_{6} \mathrm{O}_{4}\right)$ through the addition of molecular oxygen to the alkyl radical of the acid, leading to a peroxy radical. This $\mathrm{C}_{3}$ peroxy radical can then give the corresponding hydroxyl 
group $^{62}$. The reaction of CPT with limonene showed a larger variety of products, with many compounds retaining the $\mathrm{C}_{10}$ skeleton of limonene but with the addition of oxygen atoms; such products were previously observed in the reaction of another photosensitizer with limonene ${ }^{41}$. The formation of the observed product $\mathrm{C}_{17} \mathrm{H}_{21} \mathrm{O}_{3} \mathrm{~N}_{5}$, which corresponds to the formation of the recombination products (R2) of limonene and CPT, is detailed in Fig. 8 (b). Different isomers were observed, and two proposed isomeric structures are shown in Fig. 8 (b), although these could not be confirmed from the UPLC-HRMS results.

\section{Conclusions}

6-Carboxypterin proved to be an efficient photosensitizer in its singlet excited state, inducing effective electron transfer in the presence of halides, except chloride, and ubiquitous carboxylic acids. The triplet state of CPT is a less energetic photosensitizer, reflected in its limited reactivity towards halides and an organic compound, limonene. Nonetheless, the very fast electron transfer reactions to the singlet state from halides, and the somewhat slower corresponding reaction of ${ }^{3} \mathrm{CPT}$ with iodide, can lead to the formation of highly reactive $\mathrm{X}_{2}{ }^{--}$or $\mathrm{X}_{2}$, in the liquid as well as in the gas phase. Indeed, the contribution of singlet state reactivity, although fast, is mostly limited by its short lifetime. In contrast, the measured triplet state reactivity with iodide, though more than an order of magnitude smaller than the singlet state reactivity, is expected to make a larger contribution, since the lifetime of the reactive CPT component is three orders of magnitude longer than the singlet state lifetime. On the other hand, the marine concentration of bromide is at least three orders of magnitude higher than the iodide concentration, i.e. $0.84 \mathrm{mM}$ and $0.02-0.4 \mu \mathrm{M}$, respectively ${ }^{18,63}$, so the photo-oxidation of bromide by ${ }^{1} \mathrm{CPT}$ is expected to be quantitatively more important than the photo-oxidation of iodide by ${ }^{3} \mathrm{CPT}$. To illustrate the environmental relevance of 
these photochemical reactions, a very simple comparison of the oxidation of $\mathrm{I}^{-}$through the proposed photosensitized mechanism and the heterogeneous reaction with ozone showed that the photochemical pathway can account for up to $50 \%$ of the loss rate of $\mathrm{I}^{-}$. Full details of this comparison are provided in the supplementary information (ESI $\dagger$ ). As the reaction with ozone is considered the dominant pathway leading to the release of $\mathrm{I}_{2}$ in the gas phase, this simple comparison illustrates that the order of magnitude for these photochemical reactions can be highly relevant for environmental processes, although more work is needed to evaluate their exact impact.

The species produced through this photo-oxidation process can strongly influence the emission of gaseous species in the MBL; in particular, $\mathrm{X}_{2}$ can directly influence the oxidative capacity of the MBL. This suggests that photochemistry in the SML might play an important, asyet unaccounted for role in marine gas-phase chemistry and may contribute to the unexpectedly high $\mathrm{I}_{2}$ concentrations. The oxidation products of organic compounds, such as the hydroxy acid glyceric acid, have been observed globally in marine particles ${ }^{64}$. Although this has largely been attributed to gas-phase oxidation, this study demonstrates that these compounds could also originate from photochemical oxidation processes taking place in the SML. The pterins are biologically produced photosensitizers and all show interesting singlet and triplet properties, potentially leading to a non-negligible impact. Importantly, the pterins are just one family of photosensitizers present at the air-sea interface, and other photosensitizers may play the same role.

\section{Acknowledgements}

This study was supported by the European Research Council under the European Union's Seventh Framework Programme (FP/2007-2013) / ERC Grant Agreement 290852 - AIRSEA. 


\section{References}

1. W. Pfleiderer, in Chemistry and Biology of Pteridines and Folates, eds. E. J. Ayling, M. G. Nair and M. C. Baugh, Springer, New York, vol. 338, 1993, 1-17.

2. V. Herbert and J. R. Bertino, in The Vitamins, ed. P. G. N. Pearson, Academic Press, second edition, New York, 1967, 243-276.

3. E. Seibert, A. S. Chin, W. Pfleiderer, M. E. Hawkins, W. R. Laws, R. Osman and J. B. A. Ross, Biophys. J., 2002, 82, 432A-432A.

4. M. E. Hawkins, W. Pfleiderer, O. Jungmann and F. M. Balis, Anal. Biochem., 2001, 298, $231-240$.

5. H. Rokos, W. D. Beazley and K. U. Schallreuter, Biochem. Biophys. Res. Commun., 2002, 292, 805-811.

6. K. U. Schallreuter, J. Moore, J. M. Wood, W. D. Beazley, E. M. J. Peters, L. K. Marles, S.

C. Behrens-Williams, R. Dummer, N. Blau and B. Thony, J. Invest. Dermatol., 2001, 116, $167-174$.

7. K. U. Schallreuter, J. M. Wood, M. R. Pittelkow, M. Gutlich, K. R. Lemke, W. Rodl, N. N. Swanson, K. Hitzemann and I. Ziegler, Science, 1994, 263, 1444-1446.

8. K. Hirakawa, H. Suzuki, S. Oikawa and S. Kawanishi, Arch. Biochem. Biophys., 2003, 410, $261-268$.

9. P. Galland and H. Senger, Photochem. Photobiol., 1988, 48, 811-820.

10. N. Hohl, P. Galland and H. Senger, Photochem. Photobiol., 1992, 55, 239-245.

11. B. Brodhun and D. P. Hader, Photochem. Photobiol., 1990, 52, 865-871.

12. F. Gaill and A. Momzikoff, Marine Biology, 1975, 29, 315-319.

13. A. Momzikoff, R. Santus and M. Giraud, Mar. Chem., 1983, 12, 1-14. 
14. P. S. Liss and R.A. Duce, Sea Surface and Global Change, Cambridge University Press, Cambridge, 1997.

15. C. W. Fairall, D. Helmig, L. Ganzeveld and J. Hare, Atmos. Chem. Phys., 2007, 7, 443451.

16. L. Ganzeveld, D. Helmig, C. W. Fairall, J. Hare and A. Pozzer, Global Biogeochem. Cycles, 2009, 23, GB4021, doi:10.1029/2008GB003301.

17. M. W. Gallagher, K. M. Beswick and H. Coe, Q. J. R. Meteorol. Soc., 2001, 127, 539-558.

18. W. N. Chang, B. G. Heikes and M. H. Lee, Atmos. Environ., 2004, 38, 1053-1059.

19. M. Martino, B. Lézé, A. R. Baker and P. S. Liss, Geophys. Res. Lett., 2012, 39, L05809.

20. B. D'Anna, A. Jammoul, C. George, K. Stemmler, S. Fahrni, M. Ammann and A. Wisthaler, J. Geophys. Res.: Atmos., 2009, 114, D12301, doi:10.1029/2008JD011237.

21. D. Clifford, D. J. Donaldson, M. Brigante, B. D'Anna and C. George, Environ. Sci. Technol., 2008, 42, 1138-1143.

22. D. I. Reeser, A. Jammoul, D. Clifford, M. Brigante, B. D'Anna, C. George and D. J. Donaldson, J. Phys. Chem. C, 2009, 113, 2071-2077.

23. L. J. Carpenter, Chem. Rev., 2003, 103, 4953-4962.

24. R. von Glasow and P. J. Crutzen, in Treatise on Geochemistry, eds. A. Heinrich, D. Holland and Karl K. Turekian, Pergamon, Oxford, 2003, 4, 1-67.

25. S. Dixneuf, A. A. Ruth, S. Vaughan, R. M. Varma and J. Orphal, Atmos. Chem. Phys., 2009, 9, 823-829.

26. A. Saiz-Lopez and R. von Glasow, Chem. Soc. Rev., 2012, 41, 6448-6472. 
27. J. P. D. Abbatt, J. L. Thomas, K. Abrahamsson, C. Boxe, A. Granfors, A. E. Jones, M. D. King, A. Saiz-Lopez, P. B. Shepson, J. Sodeau, D. W. Toohey, C. Toubin, R. von Glasow, S. N. Wren and X. Yang, Atmos. Chem. Phys., 2012, 12, 6237-6271.

28. J. L. Thomas, A. Jimenez-Aranda, B. J. Finlayson-Pitts and D. Dabdub, J. Phys. Chem. A, 2006, 110, 1859-1867.

29. M. Martino, G. P. Mills, J. Woeltjen and P. S. Liss, Geophys. Res. Lett., 2009, 36, 5.

30. M. D. Shaw and L. J. Carpenter, Environ. Sci. Tech., 2013, 47, 10947-10954.

31. C. D. O'Dowd and G. de Leeuw, Philos. Trans. R. Soc., A, 2007, 365, 1753-1774.

32. A. Jammoul, S. Dumas, B. D'Anna and C. George, Atmos. Chem. Phys., 2009, 9, 42294237.

33. L. Tinel, S. Dumas and C. George, C. R. Chim., 2014, 17, 801-807.

34. D. J. Donaldson and V. Vaida, Chem. Rev., 2006, 106, 1445-1461.

35. B. T. Mmereki, D. J. Donaldson, J. B. Gilman, T. L. Eliason and V. Vaida, Atmos. Environ., 2004, 38, 6091-6103.

36. J. P. Putaud, R. Van Dingenen, M. Mangoni, A. Virkkula, F. Raes, H. Maring, J. M. Prospero, E. Swietlicki, O. H. Berg, R. Hillamo and T. Makela, Tellus, Ser. B, 2000, 52, $141-168$.

37. M. C. Facchini, M. Rinaldi, S. Decesari, C. Carbone, E. Finessi, M. Mircea, S. Fuzzi, D. Ceburnis, R. Flanagan, E. D. Nilsson, G. de Leeuw, M. Martino, J. Woeltjen and C. D. O'Dowd, Geophys. Res. Lett, 2008, 35, L17814, doi:10.1029/2008GL034210.

38. C. D. O'Dowd, M. C. Facchini, F. Cavalli, D. Ceburnis, M. Mircea, S. Decesari, S. Fuzzi, Y. J. Yoon and J. P. Putaud, Nature, 2004, 431, 676-680.

39. K. Z. Aregahegn, B. Noziere and C. George, Faraday Discuss., 2013, 165, 123-134. 
40. M. E. Monge, T. Rosenorn, O. Favez, M. Mueller, G. Adler, A. A. Riziq, Y. Rudich, H. Herrmann, C. George and B. D'Anna, Proc. Natl. Acad. Sci. U. S. A., 2012, 109, 68406844.

41. S. Rossignol, K. Z. Aregahegn, L. Tinel, L. Fine, B. Noziere and C. George, Environ. Sci. Tech., 2014, 48, 3218-3227.

42. C. Lorente, A. L. Capparelli, A. H. Thomas, A. M. Braun and E. Oliveros, Photochem. Photobiol. Sci., 2004, 3, 167-173.

43. S. Swarna, C. Lorente, A. H. Thomas and C. B. Martin, Chem. Phys. Lett., 2012, 542, 6265.

44. H. Thomas, C. Lorente, A. L. Capparelli, C. G. Martinez, A. M. Braun and E. Oliveros, Photochem. Photobiol. Sci, 2003, 2, 245-250.

45. H. Thomas, C. Lorente, A. L. Capparelli, M. R. Pokhrel, A. M. Braun and E. Oliveros, Photochem. Photobiol. Sci., 2002, 1, 421-426.

46. M. P. Serrano, C. Lorente, F. E. M. Vieyra, C. D. Borsarelli and A. H. Thomas, Phys. Chem. Chem. Phys., 2012, 14, 11657-11665.

47. A. Chebbi and P. Carlier, Atmos. Environ., 1996, 30, 4233-4249.

48. Y. Miyazaki, M. Sawano and K. Kawamura, Biogeosciences, 2014, 11, 4407-4414.

49. S.I. Murov, I. Carmichael and G. L. Hug, Handbook of Photochemistry, CRC Press, New York, 1993.

50. H. Rembold, in Pteridine Chemistry, eds. W. Pfleiderer and E. C. Taylor, Pergamon Press, Oxford, 1964, 465.

51. Q.H. Song and and K. C. Hwang, J. Photochem. Photobiol., A, 2007, 185, 51-56.

52. H. G. Viehe, Z. Janousek, R. Merenyi and L. Stella, Acc. Chem. Res., 1985, 18, 148-154. 
53. J.J. Aaron, M. D. Gaye, C. Párkányi, C. Boniface, T. W. N. Bieze, S. S. Atik, K. S. Raghu Veer, L. v. Szentpály and R. Ghosh, Pteridines, 1992, 3. 153-163.

54. M. Homocianu and A. Airninei, J. Mol. Liq., 2015, 209, 549-556.

55. C. Chahidi, M. Aubailly, A. Momzikoff, M. Bazin and R. Santus, Photochem. Photobiol., $1981, \mathbf{3 3}, 641-649$.

56. J. W. Ledbetter, W. Pfleiderer and J. H. Freisheim, Photochem. Photobiol., 1995, 62, 7181.

57. M. Soniat and C.B. Martin, Pteridines, 2008, 19, 120-124.

58. S. Nekkanti and C. B. Martin, Pteridines, 2015, 26, 13-22.

59. C. Lorente and A.H. Thomas, Acc. Chem. Res., 2006, 39, 395-402.

60. P.G. Seybold and W. White, Anal. Chem., 1975, 47, 1199-1200.

61. P. Jaramillo, K. Coutinho and S. Canuto, J. Phys. Chem. A, 2009, 113, 12485-12495.

62. C. von Sonntag and H.-P. Schuchmann, Angew. Chem., Int. Ed. Engl., 1991, 30, 12291253.

63. M.J. Kennish, Practical Handbook of Marine Science, CRC Press, Boca Raton, FL, 2000.

64. P. Fu, K. Kawamura and K. Miura, J. Geophys. Res.: Atmos., 2011, 116, 14. 
Table 1. Bi-molecular rate coefficients $k_{Q}$ for the efficient quenchers of singlet state CPT at neutral $\mathrm{pH}$.

\begin{tabular}{|c|c|c|c|c|}
\hline Quencher & $\mathbf{R}^{\mathbf{2}}$ & $\begin{array}{c}k \mathrm{Q} \\
\left(\mathrm{M}^{-1} \mathbf{s}^{-1}\right)\end{array}$ & $\begin{array}{c}k_{\mathrm{Q}} / \text { no. of carboxylic groups } \\
\left(\mathrm{M}^{-1} \mathrm{~s}^{-1}\right)\end{array}$ & $\begin{array}{c}\Delta G \\
(\mathrm{eV})\end{array}$ \\
\hline $\mathrm{I}^{-}$ & 0.98 & $\begin{array}{c}(4.06 \pm 0.06) \times 10^{9} \\
6.3 \times 10^{9} \mathrm{a}\end{array}$ & - & $-0.94 /-0.81$ \\
\hline $\mathrm{Br}^{-}$ & 0.99 & $(3.13 \pm 0.09) \times 10^{9}$ & - & $-0.34 /-0.21$ \\
\hline Citric acid & 0.95 & $(2.89 \pm 0.03) \times 10^{9}$ & $9.62 \times 10^{8}$ & \\
\hline Malonic acid & 0.99 & $(2.71 \pm 0.03) \times 10^{9}$ & $1.36 \times 10^{9}$ & \\
\hline Propionic acid & 0.96 & $(1.23 \pm 0.06) \times 10^{9}$ & $1.23 \times 10^{9}$ & \\
\hline Lactic acid & 0.91 & $(9.90 \pm 0.06) \times 10^{8}$ & $9.90 \times 10^{8}$ & \\
\hline
\end{tabular}


Table 2: Bi-molecular rate coefficients $k_{\mathrm{Q}}$ and free energies obtained for the reaction of ${ }^{3} \mathrm{CPT}$ with three halides.

\begin{tabular}{ccccc}
\hline Quencher & $k_{1, \mathrm{Q}}$ & $\mathrm{R}^{2}$ & $E_{\mathrm{ox}}\left(\mathrm{X}^{-} / \mathrm{X}\right)^{\mathrm{a}}$ & $\Delta G$ \\
& $\left(\mathrm{M}^{-1} \mathrm{~s}^{-1}\right)$ & & $\mathrm{V}$ & $(\mathrm{eV})$ \\
\hline $\mathrm{Cl}^{-}$ & $(2.25 \pm 1.83) \times 10^{6}$ & 0.90 & 1.36 & $0.68 / 0.88$ \\
$\mathrm{Br}^{-}$ & $(2.99 \pm 0.76) \times 10^{6}$ & 0.91 & 1.087 & $0.01 / 0.21$ \\
& & 0.90 & & $-0.59 /-0.3$ \\
$\mathrm{I}^{-}$ & $(1.89 \pm 0.22) \times 10^{8}$ & & 0.535 & 9
\end{tabular}

${ }^{\mathrm{a}}$ Values taken from ref. 49 
Table 3: Products observed by UPLC-HRMS analysis of an irradiated aqueous solution containing $0.2 \mathrm{mM} \mathrm{CPT}$ as photosensitizer

\begin{tabular}{|c|c|c|}
\hline Experiment & $\mathbf{m} / \mathbf{z}$ & Formula \\
\hline Lactic acid + & 87.009 & $\overline{\mathrm{C}_{3} \mathrm{H}_{4} \mathrm{O}_{3}}$ \\
\hline CPT & 105.019 & $\mathrm{C}_{3} \mathrm{H}_{6} \mathrm{O}_{4}$ \\
\hline Limonene + & 342.157 & $\mathrm{C}_{17} \mathrm{H}_{21} \mathrm{O}_{3} \mathrm{~N}_{5}$ \\
\hline \multirow[t]{12}{*}{ CPT } & 151.113 & $\mathrm{C}_{10} \mathrm{H}_{16} \mathrm{O}$ \\
\hline & 183.102 & $\mathrm{C}_{10} \mathrm{H}_{16} \mathrm{O}_{3}$ \\
\hline & 181.087 & $\mathrm{C}_{10} \mathrm{H}_{14} \mathrm{O}_{3}$ \\
\hline & 199.098 & $\mathrm{C}_{10} \mathrm{H}_{16} \mathrm{O}_{4}$ \\
\hline & 197.082 & $\mathrm{C}_{10} \mathrm{H}_{14} \mathrm{O}_{4}$ \\
\hline & 215.092 & $\mathrm{C}_{10} \mathrm{H}_{16} \mathrm{O}_{5}$ \\
\hline & 213.077 & $\mathrm{C}_{10} \mathrm{H}_{14} \mathrm{O}_{5}$ \\
\hline & 231.087 & $\mathrm{C}_{10} \mathrm{H}_{16} \mathrm{O}_{6}$ \\
\hline & 229.072 & $\mathrm{C}_{10} \mathrm{H}_{14} \mathrm{O}_{6}$ \\
\hline & 183.066 & $\mathrm{C}_{9} \mathrm{H}_{12} \mathrm{O}_{4}$ \\
\hline & 169.087 & $\mathrm{C}_{9} \mathrm{H}_{14} \mathrm{O}_{3}$ \\
\hline & 155.071 & $\mathrm{C}_{8} \mathrm{H}_{12} \mathrm{O}_{3}$ \\
\hline
\end{tabular}




\section{Figure captions}

Fig. 1: Absorption (solid line) and fluorescence emission (dashed line) spectrum of aqueous solutions of CPT at respectively $0.1 \mathrm{mM}, \mathrm{pH}=7.0$ and $0.1 \mu \mathrm{M}, \mathrm{pH}=7.1$.

Fig. 2: Fluorescence emission spectrum of CPT in the presence of different concentrations of $\mathrm{NaBr}$.

Fig. 3: Stern-Volmer plots of the quenching of the fluorescence of CPT in the presence of (a) the organic acids and (b) the halides as quenchers.

Fig. 4: LFP-recorded transient absorption spectrum of triplet state CPT $(0.2 \mathrm{mM})$ in deoxygenated water at $\mathrm{pH}=7.4$, recorded $450 \mathrm{~ns}(\boldsymbol{\square}), 1 \mu \mathrm{s}(\bullet)$ and $8 \mu \mathrm{s}(\diamond)$ after the laser pulse. The insert shows a zoom on the $350-600 \mathrm{~nm}$ range.

Fig. 5: LFP-recorded transient absorption spectrum of triplet state CPT $(0.1 \mathrm{mM})$ in deoxygenated aqueous solutions at $\mathrm{pH}=6.1(\boldsymbol{\square}), \mathrm{pH} 7.3(\bullet), \mathrm{pH}=8.2(\Delta)$ and $\mathrm{pH}=10.8$ $(\diamond)$ registered $450 \mathrm{~ns}$ after the laser pulse.

Fig. 6: Transient signal of triplet CPT absorption decay without quencher ( $\boldsymbol{\square})$ and in the presence of $10 \mathrm{mM} \mathrm{NaI}(\bullet)$ monitored (a) at $400 \mathrm{~nm}$ and (b) at $425 \mathrm{~nm}$.

Fig. 7: Stern-Volmer plot of the pseudo-first-order rate coefficients $k_{1 \text {,obs }}$ of ${ }^{3} \mathrm{CPT}$ quenching as a function of halide concentration. 
Fig. 8: Proposed reaction mechanism for the reaction of singlet CPT with (a) lactic acid and (b) limonene leading to the formation of observed products.

\section{Figures}

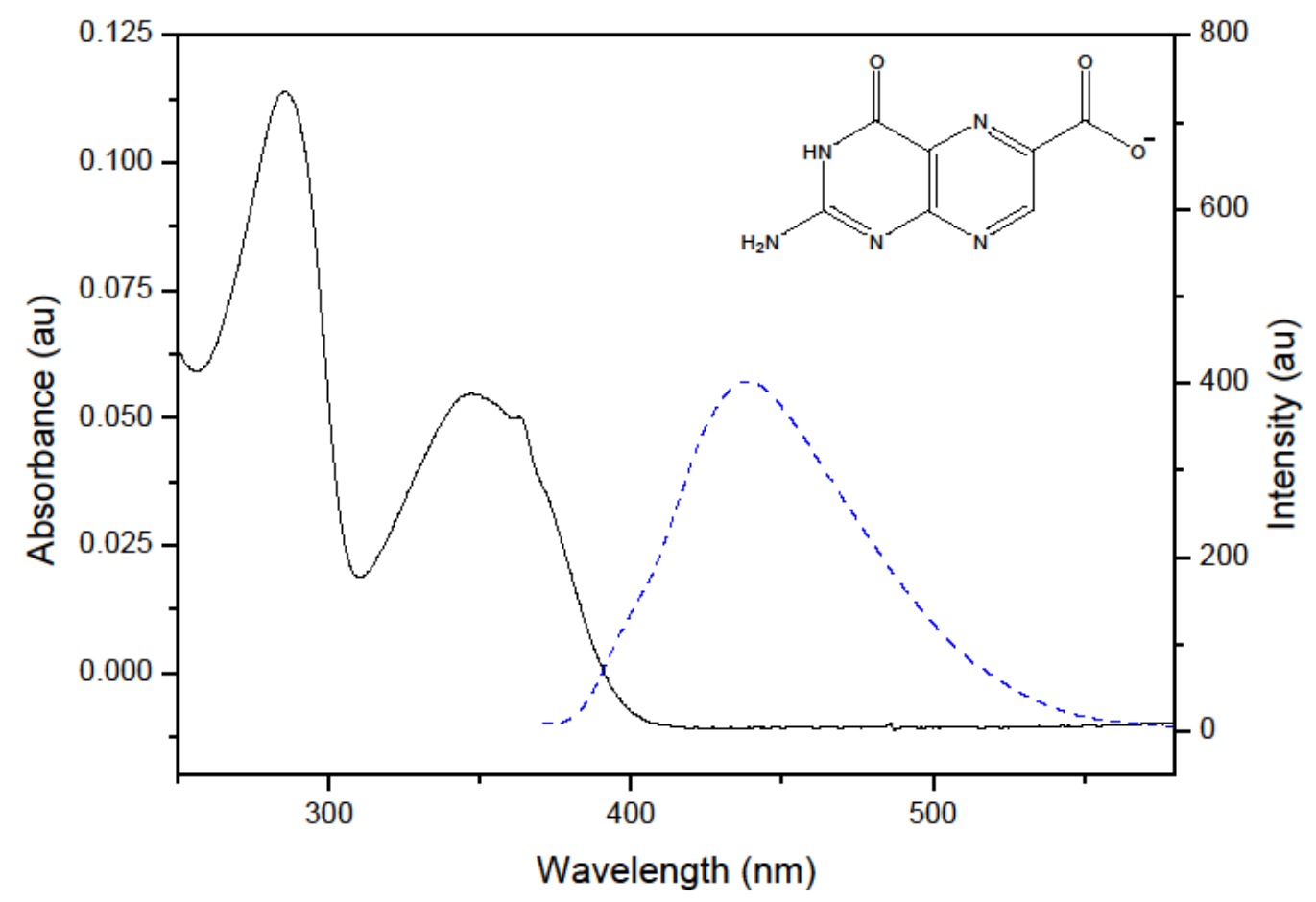

Figure 1 


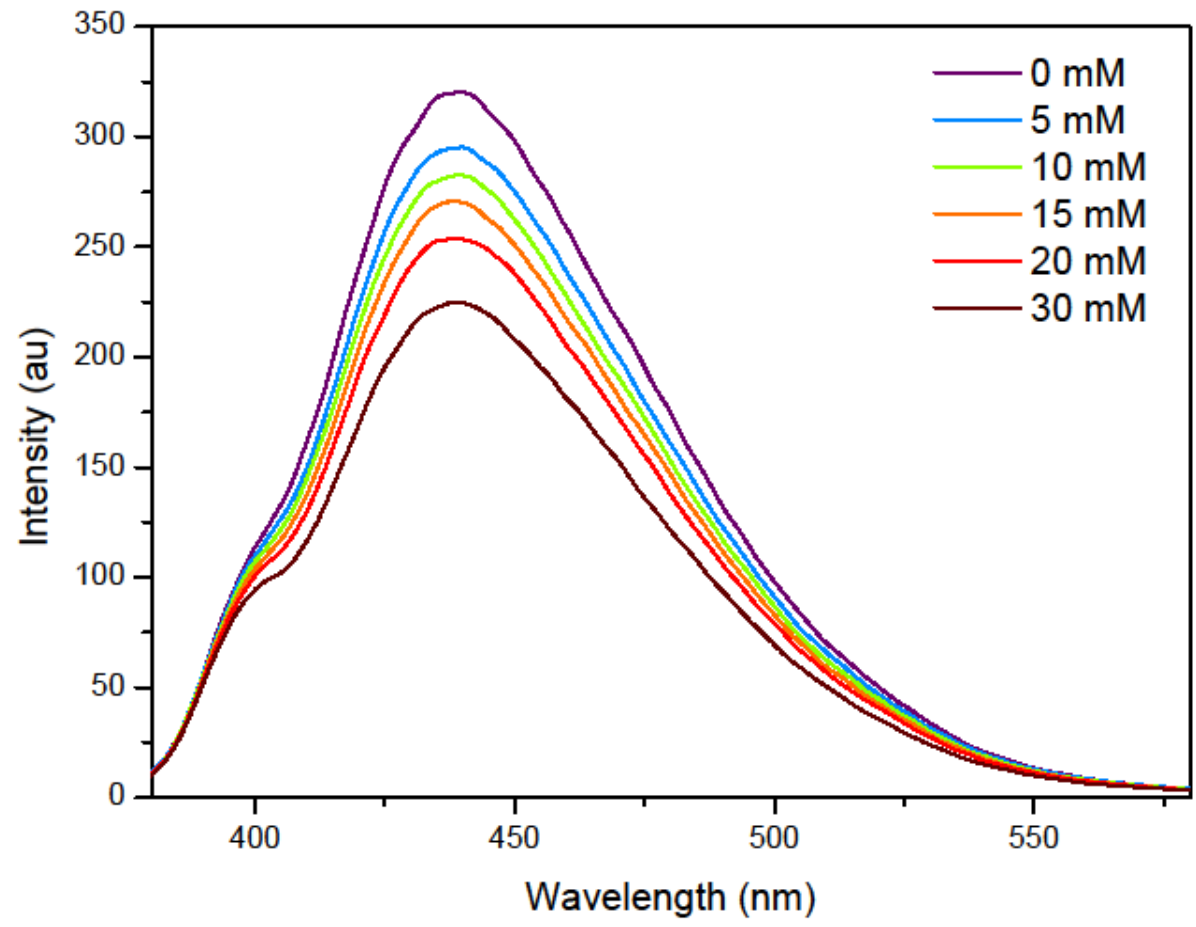

Figure 2 

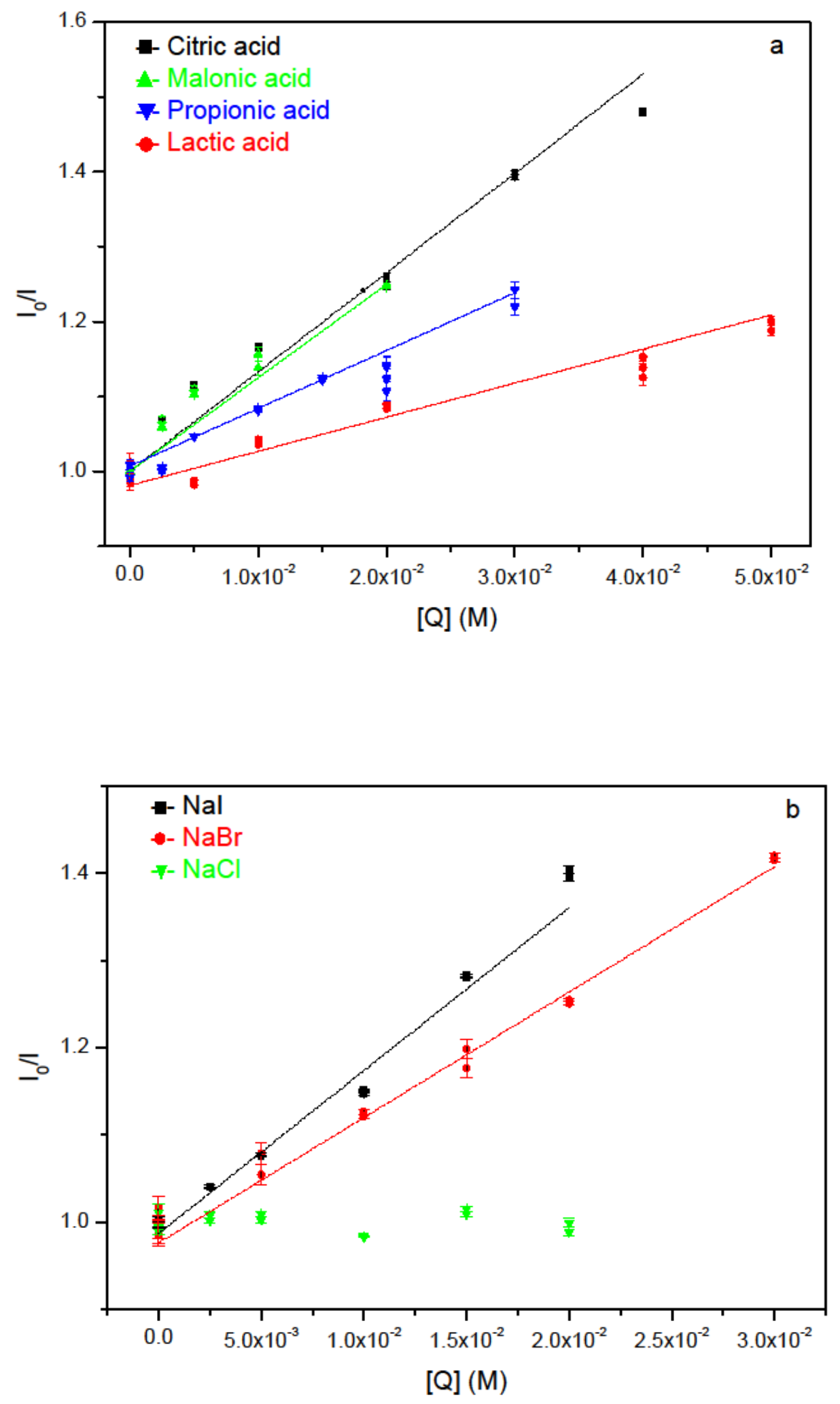
Figure 3

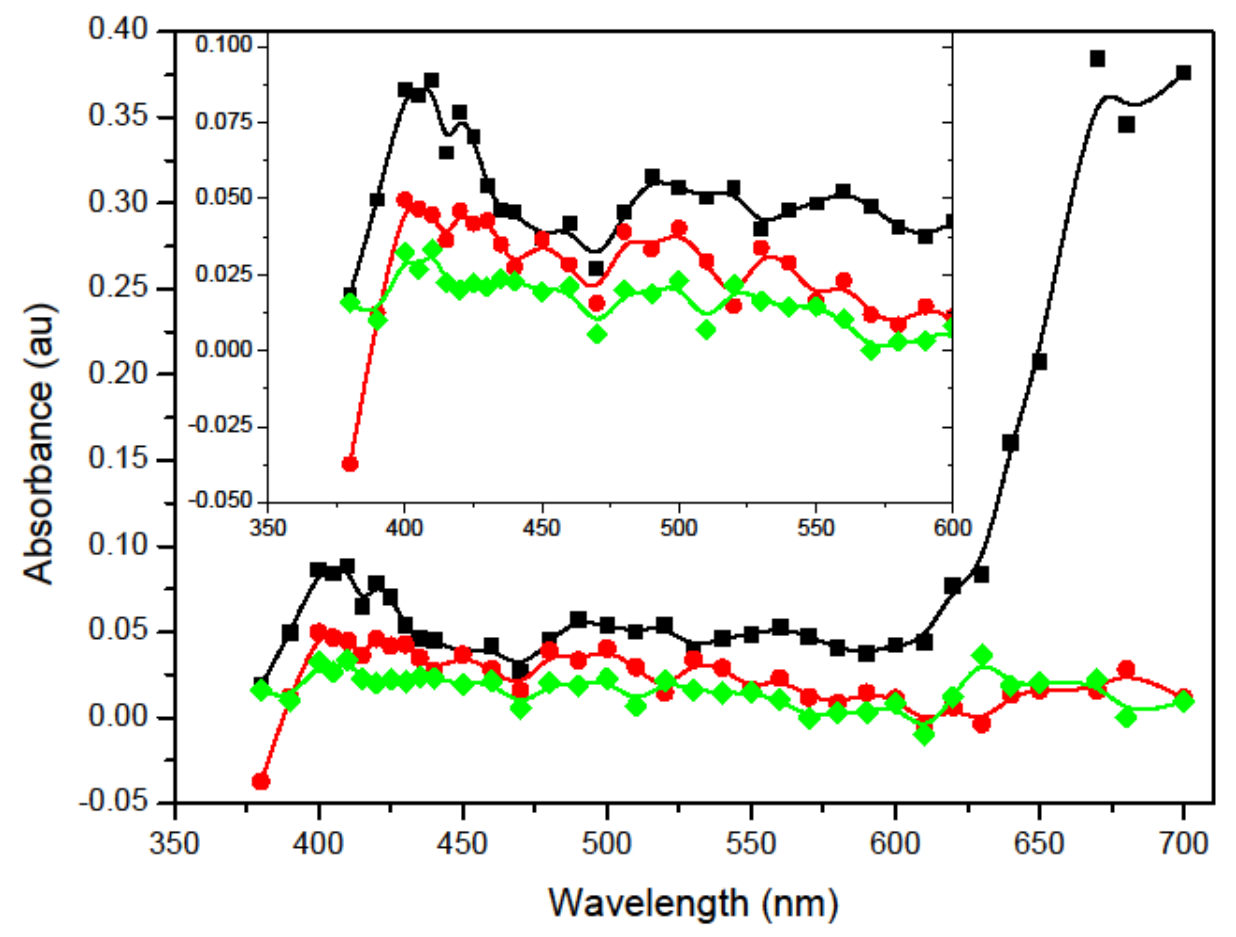

Figure 4 


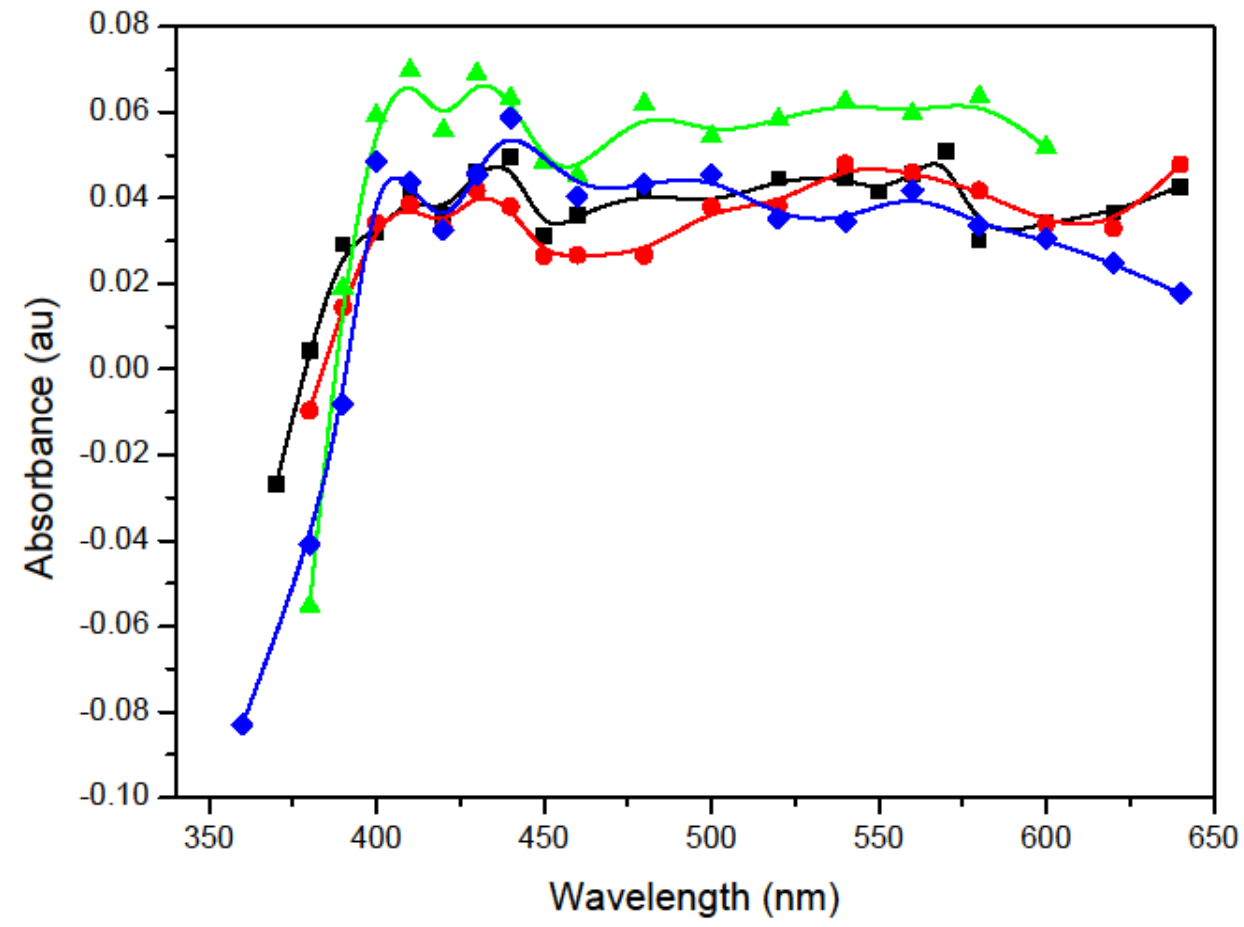

Figure 5 

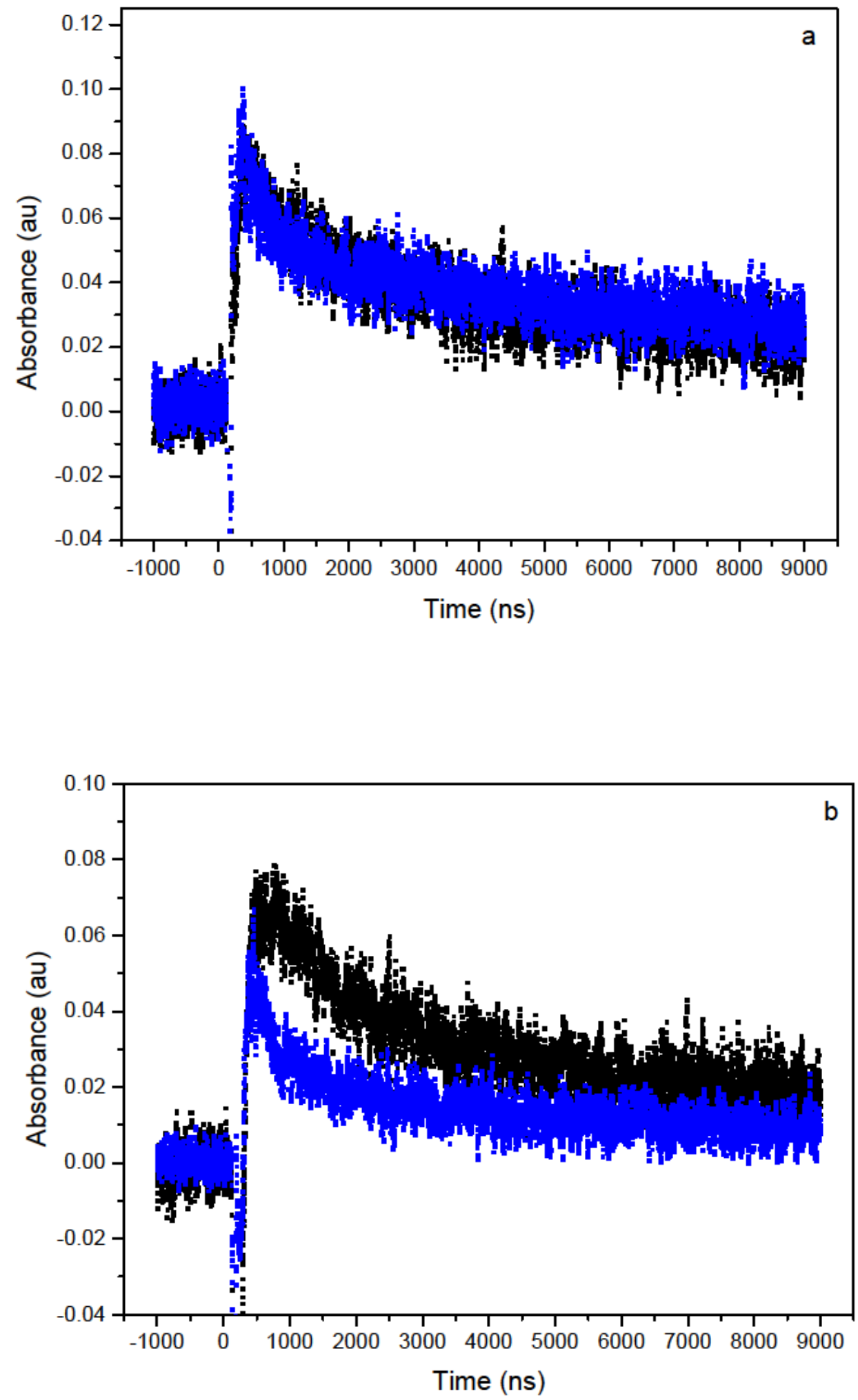
Figure 6

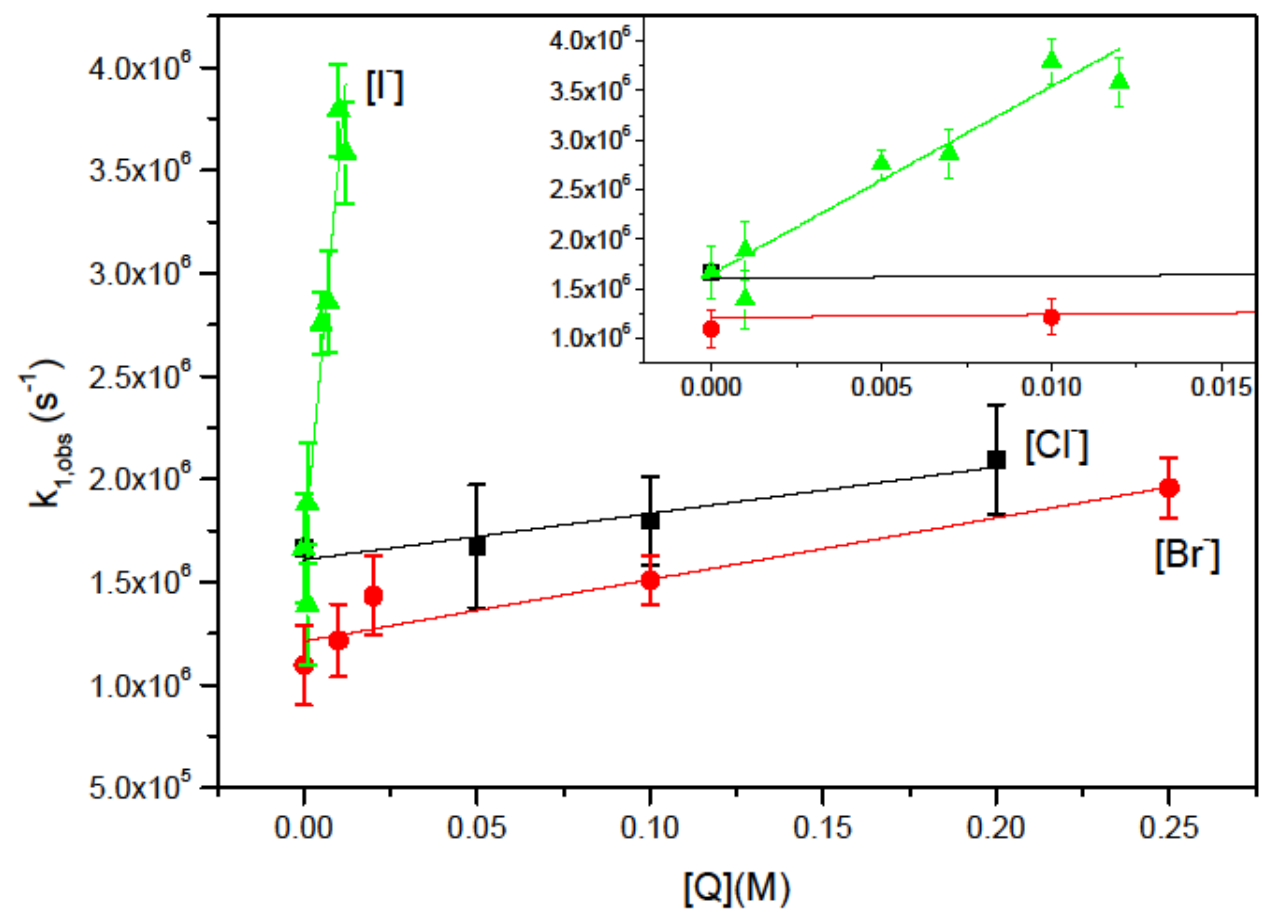

Figure 7 


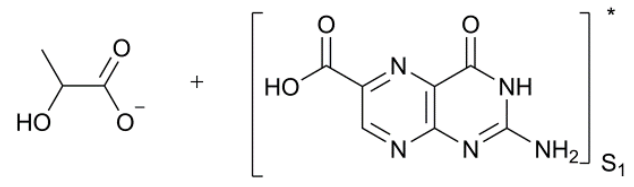

$\downarrow e^{-}$transfer
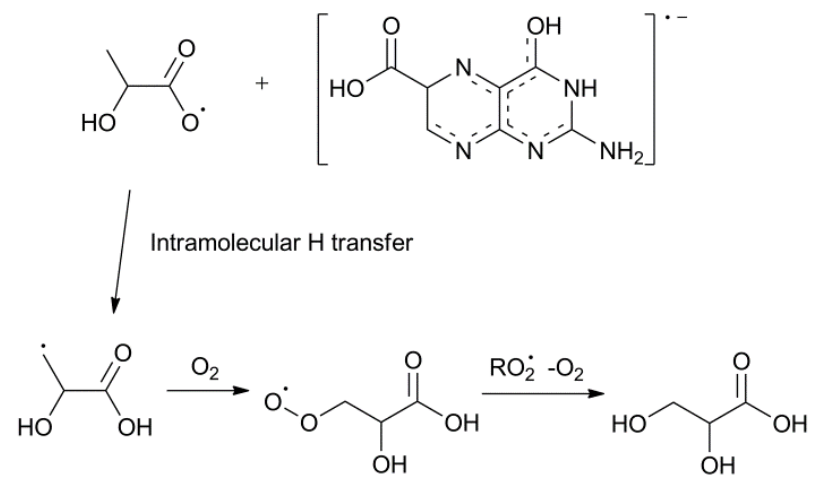

(b)
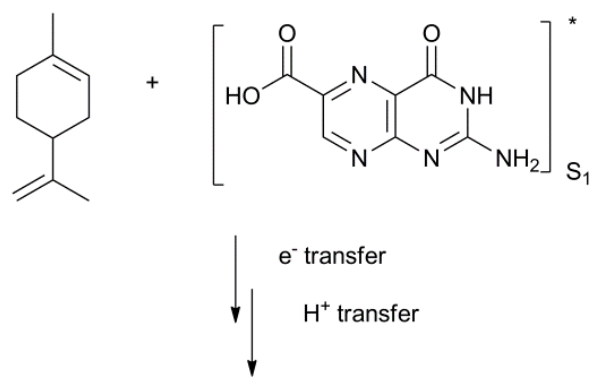

C<smiles>C=CC1CC(C)C=CC1C(=C)C</smiles><smiles></smiles>

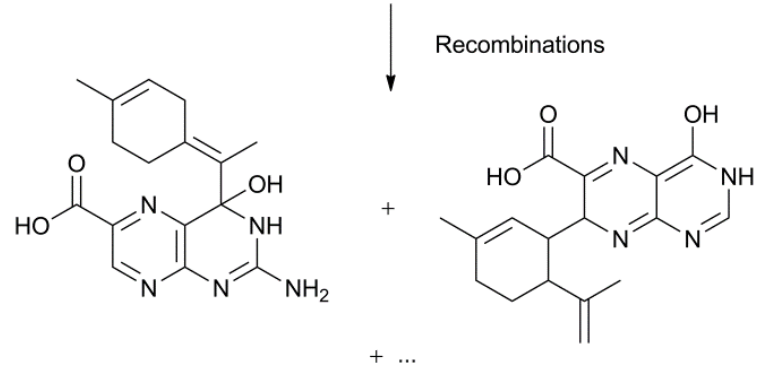

Figure 8 